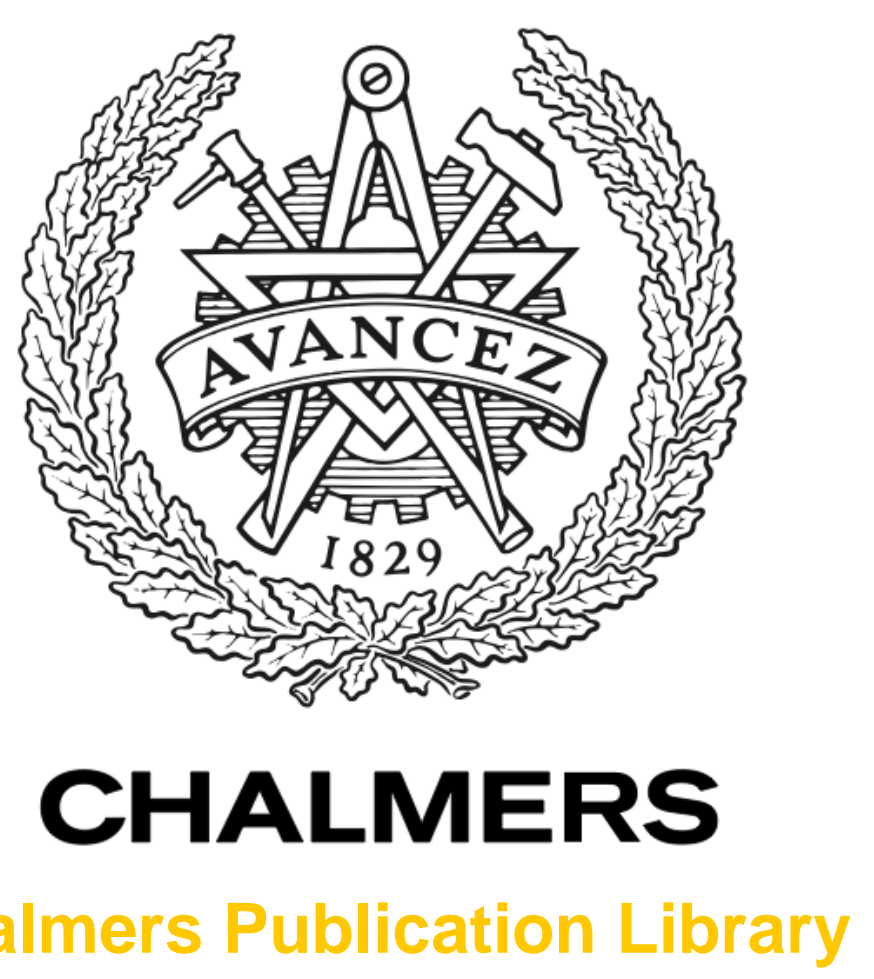

Challmers Publication Library

\title{
A multi-layer gap waveguide array antenna suitable for manufactured by die-sink EDM
}

This document has been downloaded from Chalmers Publication Library (CPL). It is the author's version of a work that was accepted for publication in:

2016 10th European Conference on Antennas and Propagation, EuCAP 2016

\begin{abstract}
Citation for the published paper:
Vosoogh, A. ; Kildal, P. ; Vassilev, V. (2016) "A multi-layer gap waveguide array antenna suitable for manufactured by die-sink EDM". 2016 10th European Conference on Antennas and Propagation, EuCAP 2016 pp. 7481259.
\end{abstract}

http://dx.doi.org/10.1109/EuCAP.2016.7481259

Downloaded from: http://publications.lib.chalmers.se/publication/246316

Notice: Changes introduced as a result of publishing processes such as copy-editing and formatting may not be reflected in this document. For a definitive version of this work, please refer to the published source. Please note that access to the published version might require a subscription.

Chalmers Publication Library (CPL) offers the possibility of retrieving research publications produced at Chalmers University of Technology. It covers all types of publications: articles, dissertations, licentiate theses, masters theses, conference papers, reports etc. Since 2006 it is the official tool for Chalmers official publication statistics. To ensure that Chalmers research results are disseminated as widely as possible, an Open Access Policy has been adopted.

The CPL service is administrated and maintained by Chalmers Library. 


\title{
A Multi-Layer Gap Waveguide Array Antenna Suitable for Manufactured by Die-Sink EDM
}

\author{
Abbas Vosoogh ${ }^{1}$, Per-Simon Kildal ${ }^{2}$, and Vessen Vassilev ${ }^{3}$ \\ ${ }^{1}$ Department of Signals and Systems, Chalmers University of Technology, Gothenburg, Sweden, abbas.vosoogh@chalmers.se \\ ${ }^{2}$ Department of Signals and Systems, Chalmers University of Technology, Gothenburg, Sweden, per-simon.kildal@chalmers.se \\ ${ }^{3}$ Department of Microtechnology and Nanoscience, Microwave Electronics, Gothenburg, Sweden, vessen.vassilev@chalmers.se
}

\begin{abstract}
In this paper, a multilayer wideband slot array antenna is presented for high gain applications at V-band. The proposed antenna consists of three unconnected metal layers based on the recently introduced gap waveguide technology. A $\mathbf{2} \times \mathbf{2}$ cavity-backed slot subarray is fed by a ridge gap waveguide corporate distribution network. The subarray is optimized to have wide bandwidth and low grating lobes in an infinite array environment. A simple slot-tilting method is used to fulfill the radiation pattern requirement of the ETSI 302 standard for fixed radio links. A prototype consisting of $16 \times 16$ slots is manufactured by die-sink Electric Discharge Machining (EDM), a fast modern planar-3D spark machining method. The measured antenna has a relative bandwidth of $18 \%$ with input reflection coefficient better than $-10 \mathrm{~dB}$, and the radiation patterns satisfy the ETSI 302 standard co-polar sidelobe envelope over 56-67 $\mathrm{GHz}$ frequency band. The measured total aperture efficiency is over most of the frequency band better than $80 \%$.
\end{abstract}

Keywords-EDM, gap waveguide, high efficiency, millimeter wave, slot array antenna.

\section{INTRODUCTION}

High gain and low loss planar array antennas for point-topoint high data rate wireless links at millimeter waves have received a lot of attention over the last few years. Hollowwaveguide slot arrays are suitable for applications requiring high gain antennas. A corporate-fed rectangular waveguide slot array with high efficiency is reported in [1], manufactured by diffusion bonding of laminated thin copper plates. Substrate Integrated Cavity (SIC) array antennas [2]-[3] and Substrate Integrated Waveguide (SIW) arrays [4]-[6] are the other interesting planar technologies which have been investigated and developed recently.

The antenna efficiency is one of the most important parameters of large antennas [7, Sec. 2.5.2]. This is the product of the mismatch factor, the radiation efficiency and the aperture efficiency, and it is in large arrays mainly affected by the radiation efficiency due to losses in the distribution network [6]. Microstrip and SIW array antennas suffer from high dielectric loss and have a relatively low efficiency specially for a large aperture dimension at millimeter wave frequencies [4],[5]. Manufacturing costs and assembly issues in order to achieve good electrical contact between different parts are the main challenges of hollow waveguide slot array antennas at high frequencies. The purpose of the present paper is to present a similar work as [1], manufactured by an alternative fast

This work has been financially supported by the Swedish Governmental Agency for Innovation Systems VINNOVA via a project within the VINN Excellence center Chase and the European Research Council (ERC) under the $7^{\text {th }}$ Framework Program ERC grant number 321125. method by which electrical contact is not needed between three different metal layers.

As an alternative to the traditional guiding structures, the gap waveguide demonstrates interesting characteristics such as low loss, manufacture flexibility, and cost effectiveness especially at millimeter wave frequencies. The gap waveguide technology was introduced in [8]-[9]. It is based on a parallelplate waveguide configuration and using soft/hard boundary conditions to control the propagation of waves in desired directions between the two plates. One of the advantages of this new guiding structure is that there is no need for electrical contact between the parallel-plate layers. Therefore, gap

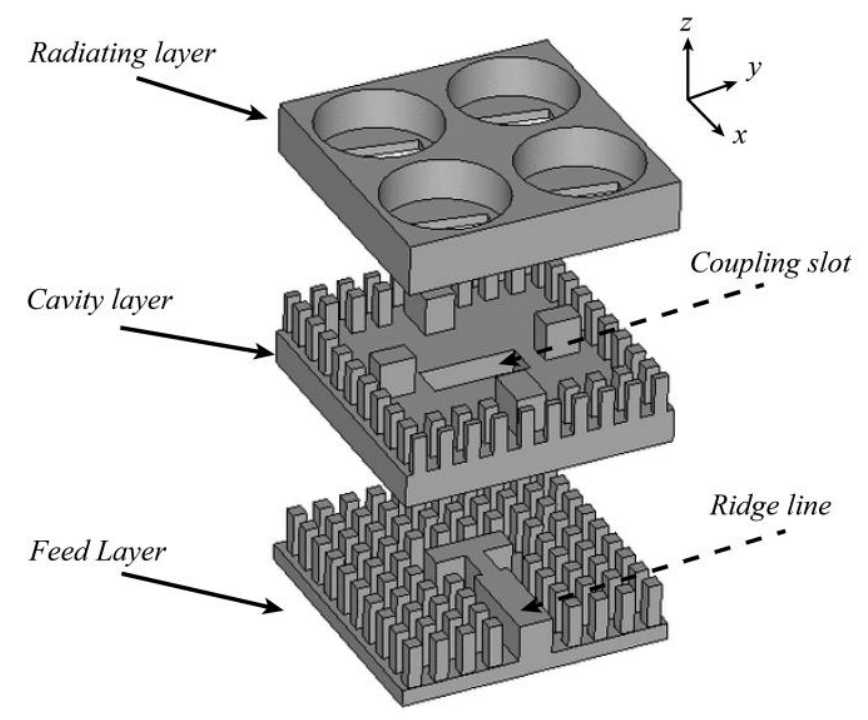

(a)
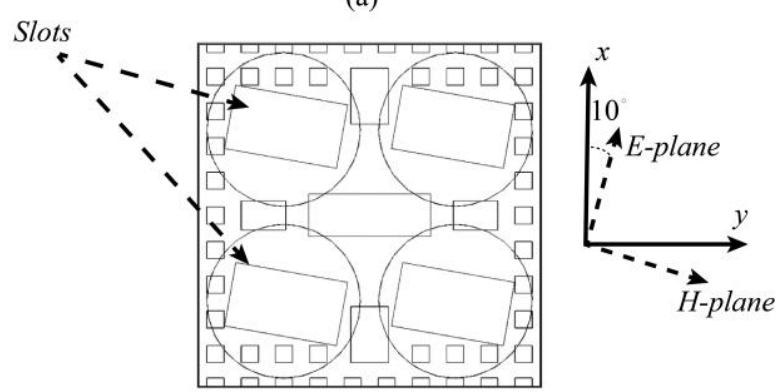

(b)

Fig. 1 The geometry of the cavity-backed $2 \times 2$ slot subarray. 


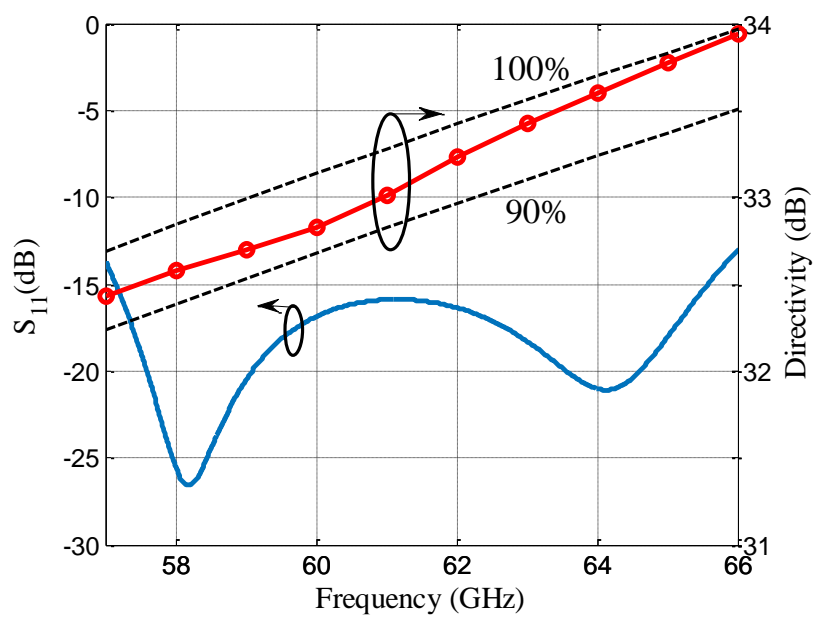

Fig. 2. Computed reflection coefficient of $2 \times 2$ slot subarray and directivity of an array with $16 \times 16$ slot aperture dimension in infinite array environment. The $100 \%$ and $90 \%$ lines corresponds to antenna efficiencies.

waveguide-based distribution networks can be manufactured by molding or planar-3D manufacturing methods such as diesink Electric Discharge Machining (EDM), and thereby offers mechanical advantage and flexibility.

Several array antennas and filters based on four different varieties of gap waveguide structure: ridge gap waveguide [9], groove gap waveguide [10], microstrip gap waveguide [11], and inverted microstrip-ridge gap waveguide [12], are reported in the literature. Gap waveguide planar array antennas [14][17] and bandpass filter and diplexer[18],[19], which thereby all could be integrated with the feed network are developed over the last few years. Moreover, the gap waveguide technology can be used to package active circuits [20],[21]

In this paper, a corporate-fed slot array antenna with high gain, high efficiency and wide impedance bandwidth is presented. A new wide bandwidth air-filled cavity-backed $2 \times 2$ slot subarray is designed to cover the whole unlicensed $60 \mathrm{GHz}$ frequency band. The radiation performance is one of the specifications for the high gain fixed radio links. The array antennas presented in [1]-[6] did not fulfill the sidelobe requirement of the ETSI EN 302 standard for terrestrial fixed radio systems [22]. In the current paper we use a simple tiltedslot technique to improve the radiation pattern of the antenna in E- and H-planes. A $16 \times 16$ slot array is designed and fabricated by die-sink EDM. The slots are excited with the same phase and amplitude to achieve maximum directivity.

\section{ARRAY ELEMENT DESIGN}

Fig. 1 shows the geometry of the proposed multi-layer $2 \times 2$ cavity-backed slot subarray. Four radiating slots with spacing smaller than, but close to one wavelength are fed by an airfilled groove gap waveguide cavity. In order to decrease mutual coupling between the slots, and thereby to increase the unit cell bandwidth as well as to suppress the grating lobes, we use a circular waveguide cavity outside each radiating slot element. Each $2 \times 2$ subarray is fed via a coupling slot with a ridge gap waveguide distribution network on the bottom layer.

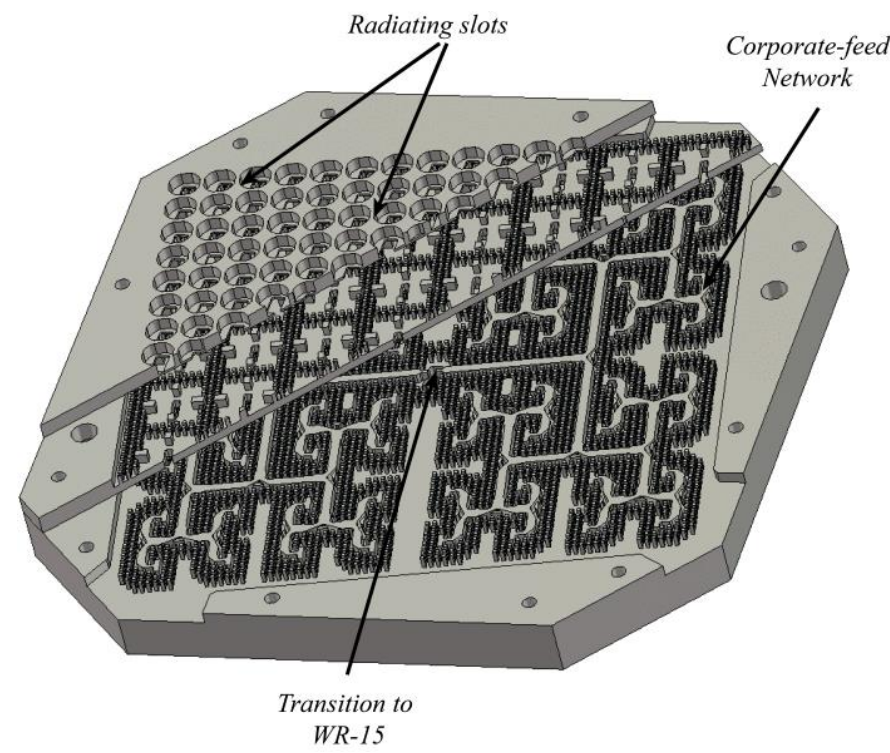

Fig. 3. Configuration of the proposed three-layer corporate-fed $16 \times 16$ slot array antenna.

The pin surfaces together with the small air gaps between the three metal layers create the stopband and suppress undesired parallel-plate modes and leakage between the cavities and the ridges of the distribution layer.

The radiating slots are tilted $10^{\circ}$ with respect to the principle planes of the array in order to achieve lower sidelobes in E- and H-planes and thereby fulfill the requirements of the ETSI EN 302 standard for the co-polar sidelobe level. Fig.1 (b) shows the tilted slots together with the definitions of the principle $x z$ - and $y z$-planes of the array and the E- and $\mathrm{H}$ planes. By tilting the slots the E- and H-planes of the antenna separates from the principle planes of the array.

The designed subarray has $8 \times 8 \mathrm{~mm}^{2}$ size. In order to avoid high grating lobes in array antennas, the element spacing is required to be smaller than one wavelength. A simple formula is presented in [23] to calculate the aperture efficiency reduction due to grating lobes in planar array antennas. The amplitude and phase variations within the subarray may cause grating lobes due to the large subarray spacing. The subarray is

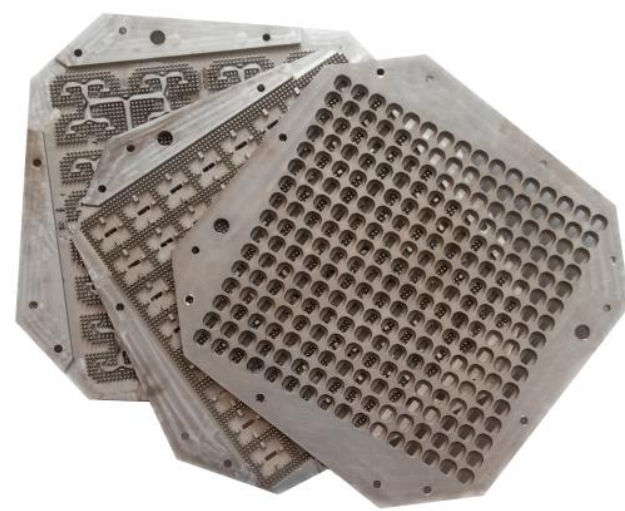

Fig. 4. Photograph of the proposed $16 \times 16$ slot array antenna fabricated by die-sink EDM. 


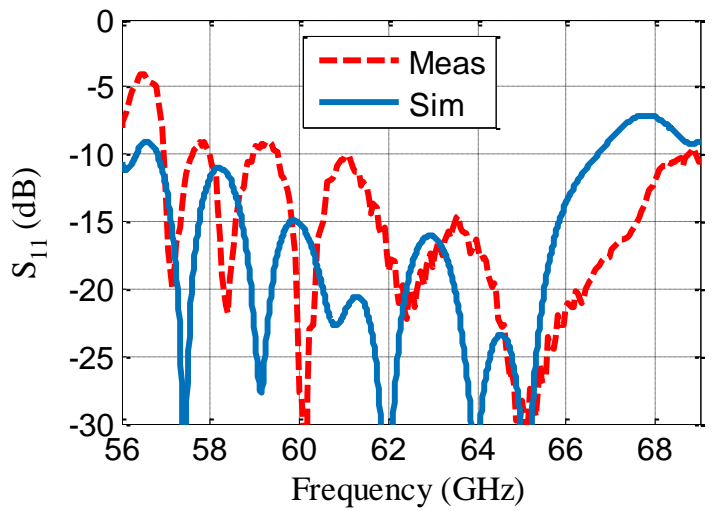

Fig. 5. Comparison of simulated and measured input reflection coefficient of the proposed $16 \times 16$ slot array.

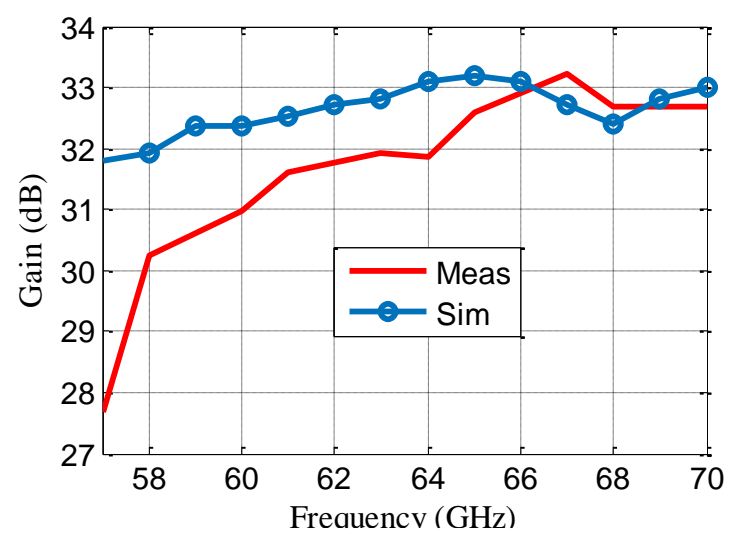

Fig. 6. Measured and computed realized gain of $16 \times 16$ slot array antenna.

optimized in the infinite array environment to have wide bandwidth and low grating lobes by using CST Microwave studio.

Fig. 2 shows the simulated reflection coefficient of the proposed subarray in the infinite array environment. The directivity of an array with $16 \times 16$ slot aperture dimension is also shown in Fig. 2. The dashed lines show the maximum available directivities with $100 \%$ and $90 \%$ aperture efficiency. This figure shows that the designed subarray has high aperture efficiency.

\section{MEASURED $16 \times 16$ SLOT ARRAY ANTENNA}

A $16 \times 16$-element slot array antenna was designed by using the proposed $2 \times 2$ cavity-backed slot subarray. The configuration of the array is shown in Fig. 3. The antenna consists of three unconnected metal layers with a small gap between each layer. Thereby, the proposed antenna has a simple mechanical assembly without any requirement of electrical contact between the building blocks. A corporate distribution network was designed in ridge gap waveguide to feed all subarrays with equal phase and amplitude. A wideband and compact transition between standard WR-15 rectangular waveguide and ridge gap waveguide was designed as well. Fig. 4 shows the photograph of the prototype fabricated by diesink EDM technique. The total size of the antenna is $80 \times 80$ $\mathrm{mm}^{2}$ whereas the actual array aperture size is $64 \times 64 \mathrm{~mm}^{2}$. The

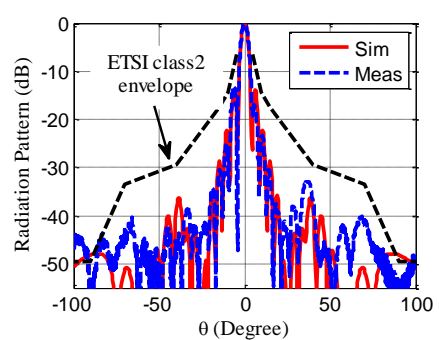

(a)

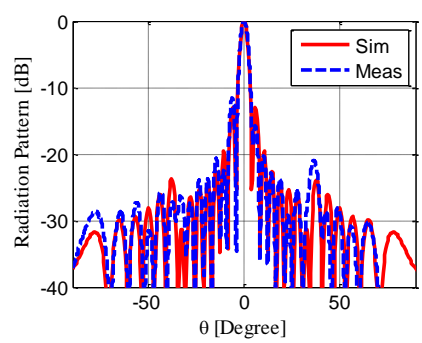

(c)

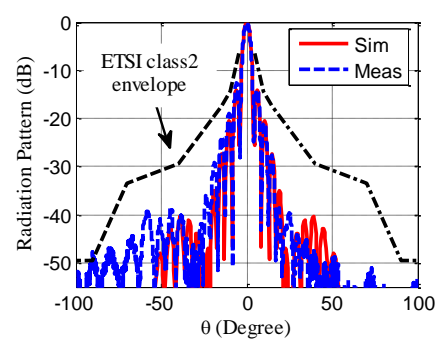

(b)

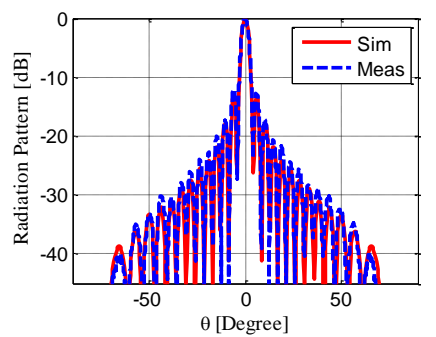

(d)
Fig. 7. Simulated and measured radiation patterns of the proposed array antenna at $64 \mathrm{GHz}$. (a) E-plane, (b) H-plane, (c) principle E-plane, and (d) principle H-plane.

measured and simulated input reflection coefficient of the prototype are shown in Fig. 5. The simulated reflection coefficient is below $-10 \mathrm{~dB}$ from $56-67 \mathrm{GHz}$. There is some discrepancy between simulated and measured results which is due to the manufacturing tolerances. The realized gain of the antenna at the boresight is shown in Fig. 6. Fig.7 shows the simulated co-polar far field patterns of the proposed antenna in the different planes at $64 \mathrm{GHz}$. The Class II ETSI EN 302 sidelobe envelope requirement is also illustrated. The co-polar sidelobes are below the standard envelope in both the E- and H-plane. The design can be extended to a larger array to satisfy the stricter Class III ETSI EN 302 standard.

\section{CONCLUSION}

In this paper, we have presented a high gain, high efficiency, and wideband planar array antenna at V-band, suitable for volume production by a cost-effective method, i.e., die-sink EDM. This is probably the first time this manufacture method has been used for large gain antennas, and certainly the first time it is used for planar $60 \mathrm{GHz}$ arrays. The subarray shows better radiation patterns and higher aperture efficiency than the presented unit cells in [14] and [17]. A corporate-fed $16 \times 16$ slot array antenna has been designed with the proposed subarray. The designed array antenna consists of $8 \times 8$ air-filled subarrays fed by a ridge gap waveguide distribution network. The simulated and measured results show wide impedance bandwidth and good radiation patterns. The proposed antenna satisfies the class II sidelobe envelope requirement of the ETSI EN 302 standard.

\section{ACKNOWLEDGMENT}

The authors are grateful to Zhixing Chen at Guangdong Shenglu Telecommunication (Shenglu) for doing the 
measurements at Shenglu's outdoor range in China.

\section{References}

[1] Y. Miura, J. Hirokawa, M. Ando, Y. Shibuya and G. Yoshida, "Doublelayer full-corporate-feed hollow-waveguide slot array antenna in the 60GHz band," IEEE Trans. Antennas Propag., vol. 59, no. 8, pp. 2844 2851, Aug. 2011.

[2] B. Cao, H. Wang, Y. Huang and J. Zheng, "High-gain L-prob exited substrate integrated cavity antenna array with LTCC-baced gap waveguide feeding network for W-band application," IEEE Trans. Antennas Propag., Sep. 2015.

[3] B. Cao, H. Wang, Y. Huang, "W-band high gain $\mathrm{TE}_{220}$-mode slot antenna array with gap waveguide feeding network," IEEE Antenna Wireless Propag. Lett., Oct. 2015.

[4] Y. J. Cheng, Y. X. Guo, and Z. Q. Liu, "W-Band large-scale high-gain planar integrated antenna array," IEEE Trans. Antennas Propag., vol. 62, no. 6, pp. 3370-3373, Jun. 2014.

[5] J. Wu, Y. J. Cheng and Y. Fan, "A wideband high-gain high-efficiency hybrid integrated plate array antenna for V-Band inter-satellite links," IEEE Trans. Antennas Propag., vol. 63, no. 4, pp. 1225-1233, Apr. 2015.

[6] Y. Li and K-M. Lik, "60-GHz substrate integrated waveguide fed cavitybacked aperture-coupled microstrip patch antenna arrays," IEEE Trans. Antennas Propag., vol. 63, no. 3, pp. 1075-1085, March 2015.

[7] P. S. Kildal, Foundations of Antennas: A Unified Approach for Line-ofSight And Multipath, Kildal Antenn AB, 2015 (free PDF available at www.kildal.se).

[8] P. -S. Kildal, E. Alfonso, A. Valero-Nogueira, and E. Rajo-Iglesias, "Local metamaterial-based waveguides in gaps between parallel metal plates," IEEE Antenna Wireless Propag. Lett., vol. 8, pp. 84-87, 2009.

[9] P.-S. Kildal, "Three metamaterial-based gap waveguides between parallel metal plates for mm/submm waves," 3rd European Conference on Antennas and Propagation EuCAP 2009, 2009.

[10] P.-S. Kildal, A. Uz Zaman, E. Rajo-Iglesias, E. Alfonso, A. ValeroNogueira, "Design and experimental verification of ridge gap waveguides in bed of nails for parallel plate mode suppression", IET Microwaves, Antennas \& Propagation, vol. 5, no 3, pp. 262-270, February 2011.

[11] E. Rajo-Iglesias and P.-S. Kildal, “Groove gap waveguide: A rectangular waveguide between contactless metal plates enabled by parallel-plate cut-off', 4th European Conference on Antennas and Propagation EuCAP 2010, Barcelona, Spain, 12-16 April 2010.

[12] A. Algaba Brazalez, A. Uz Zaman, P.-S. Kildal, "Improved microstrip filters using PMC packaging by lid of nails", IEEE Transactions on
Components, Packaging and Manufacturing Technology, vol. 2, no. 7, July 2012.

[13] A. Valero-Nogueira, M. Baquero, J.I. Herranz, J. Domenech, E. Alfonso and A. Vila, "Gap waveguides using a suspended strip on a bed of nails", IEEE Antennas and Wireless Propagation Letters, vol. 10, pp. 1006-1009, 2011.

[14] A. Vosoogh and P. S. Kildal, "High Efficiency $2 \times 2$ Cavity-Backed Slot Sub-array for $60 \mathrm{GHz}$ Planar Array Antenna Based on Gap Technology," International Symposium on Antennas and Ppagation ISAP2015, Hobart, Tasmania, 9-12 ${ }^{\text {th }}$ November 2015.

[15] A. U. Zaman and P. S. Kildal, "Wideband slot antenna array with singlelayer corporate feed-network in ridge gap waveguide technology", IEEE Trans. Antennas and Propag., vol. 62, no. 6, pp- 2992- 3001, Jun 2014.

[16] E. Pucci, E. Rajo-Iglesias, J.-L. Vazquez-Roy and P.-S. Kildal, "Planar Dual-Mode Horn Array with Corporate-Feed Network in Inverted Microstrip Gap Waveguide", IEEE Trans. Antennas and Propag., vol. 62, no. 7, pp. 3534-3542, Jul. 2014.

[17] S. A. Razavi, P. -S. Kildal, L. Xiang, E. Alfonso, and H. Chen, " $2 \times 2-$ slot element for $60 \mathrm{GHz}$ planar array antenna realized on two doubledsided PCBs using SIW cavity and EBG-type soft surface by microstripridge gap waveguide," IEEE Trans. Antennas Propag., vol. 62, no. 9, pp. 4564-4573, Sep. 2014.

[18] E. Alfonso Alos, A. U. Zaman, and Per-Simon Kildal, "Ka-band Gap Waveguide Coupled-Resonator Filter for Radio Link Diplexer Application", IEEE Transactions on Components, Packaging and Manufacturing Technology, Vol. 3, No. 5, pp. 870-879, November 2012.

[19] M. Rezaee, A. U. Zaman, P.-S. Kildal, "V-Band Groove Gap Waveguide Diplexer", EuCAP 2015, Lisbon, Portugal, 12-17 April 2015.

[20] E. Rajo-Iglesias, A. Uz Zaman, P.-S. Kildal, "Parallel plate cavity mode suppression in microstrip circuit packages using a lid of nails", IEEE Microwave and Wireless Components Letters, vol. 20, no. 1, pp. 31- 33, Dec. 2009.

[21] A.U. Zaman, T. Vukusic, M. Alexanderson, P.-S. Kildal, "Gap Waveguide PMC Packaging for Improved Isolation of Circuit Components in High Frequency Microwave Modules", IEEE Transactions on Components, Packaging and Manufacturing Technology, vol. 4, no. 1, pp. 16-25, Jul. 2013.

[22] Fixed Radio Systems Characteristics and Requirements; Final Draft, ETSI EN 302 217-4-2 V1.5.1 (2010-01), ETSI [Online]. Available: http://www.etsi.org/WebSite/homepage.aspx.

[23] A. Vosoogh and P. S. Kildal, "Simple Formula for Aperture Efficiency Reduction Due to Grating Lobes in Phased Arrays," submited to IEEE Trans. Antennas Propag., 2015. 